\title{
Revolución y Constitución en la obra de Silvio Zavala, 1930-1932
}

\author{
Andrés Lira*
}

\begin{abstract}
The early works of Silvio Zavala — published between 1930 and 1932 — when he was a law student in Mexico and in Spain, show his interest in constitutional law and the political environment of his time. He dedicated himself to the study of the Mexican Constitutional Convention of 1917 and the constitutional activity of the Spanish Republic. He found, in the first, the institutional beginnings of the winning faction in the fighting which followed the Mexican Revolution; in the second, the disagreements and the impossibility of consensus among the protagonists who participated within and outside the Spanish parlament (warning of repression and the civil war that would come later). The thematic sequence of these short articles published in Mexico in the Revista de Ciencias Sociales de la Facultad de Jurisprudencia, in the daily El Nacional and in journals such as Universidad de México and Crisol offers an interesting comparative view which we should consider to be the first installments of the historiographical work of a great historian of colonial American institutions, who discovered and confirmed his vocation in the years that preceded the end of the Spanish Civil War.
\end{abstract}

Key words: Revolution, Constitution, political parties, politics, religion.

\section{RESUMEN}

La obra temprana de Silvio Zavala — publicada entre 1930 y 1932, cuando era estudiante de derecho en México y en España- muestra su interés por 
el acontecer político de sus días. Se ocupó del Constituyente mexicano de 1917 y del momento constitucional de la República Española. Vio en el primero la realización institucional del triunfador en la lucha de facciones que siguió a la revolución armada; en el segundo, la discordia e imposibilidad de acuerdo entre los protagonistas que actuaban dentro y fuera del parlamento español (augurio de represiones y de la guerra civil que vendría más tarde). La secuencia temática de esos breves artículos, publicados en México en la Revista de Ciencias Sociales de la Facultad de Jurisprudencia, en El Nacional y en las revistas Universidad de México y Crisol, ofrece una interesante visión comparativa que debemos apreciar como preludio de la obra historiográfica del gran historiador de las instituciones coloniales americanas, que descubrió y afirmó su vocación en los años que precedieron al desenlace de la Guerra Civil Española.

Palabras clave: revolución, constitución, partidos políticos, politica, religión.

\section{Preámbulo}

Me ocuparé de un Silvio Zavala poco conocido — por no decir 1 desconocido - , anterior al historiador que reconocemos a partir de Los intereses particulares en la conquista de la Nueva España, tesis de doctorado en derecho que defendió el 11 de octubre de 1933 en la Universidad Central de Madrid, a sus 27 años de edad. La calidad de este trabajo le valió la beca de la Junta de Ampliación de Estudios e Investigaciones Científicas en el Centro de Estudios Históricos de Madrid, que dirigía Ramón Menéndez Pidal, en cuya Sección Hispanoamericana elaboró dos libros, Las instituciones jurídicas en la conquista de América y La encomienda indiana, que aparecieron en 1935 como primeros títulos publicados por la Sección Hispanoamericana. Esas fueron las primicias de la inmensa obra historiográfica de Silvio Zavala, desarrollada en los siguientes tercios del siglo $\mathrm{xx},{ }^{1} \mathrm{y}$ que, debido a su abundancia, creatividad y variedad, ha dejado fuera de consideración al jurista y observador crítico del momento político que se perfilaba en el joven estudiante de derecho, de lo cual tenemos evidencias a las que debemos atender, por el interés que tienen en sí mismas y porque nos ayudan a comprender su penetración como historiador de las instituciones.

En efecto, la obra temprana de Silvio Zavala, publicada en los años 19301932, cuando era estudiante de derecho en México y en España, revela interés por el derecho constitucional, atenta observación del entorno político, claridad de propósito y de expresión y secuencia temática. 
Llegó a la ciudad de México a finales de 1928, cuando tenía 19 años, para inscribirse en la Escuela de Jurisprudencia de la Universidad Nacional y continuar los estudios que había iniciado en la Universidad Nacional del Sureste, Mérida, Yucatán, donde cursó los dos primeros años. En la capital de la República Mexicana terminó con buen éxito el tercero y el cuarto y, el 18 de marzo de 1931, cuando cursaba el quinto y último año, fue electo por unanimidad y aclamación, delegado como ganador de la beca que ofrecía el gobierno español a estudiantes mexicanos para terminar los estudios de derecho en la Universidad Central de Madrid.

Entre las razones que adujeron los miembros de la Sociedad de Alumnos del Quinto Año ante el secretario general de la Universidad Nacional, para afirmar la validez de la elección, además de la calidad académica y cualidades personales del candidato ("profundidad de sus conocimientos, modestia y compañerismo"), advirtieron el beneficio que resultaría de su estancia en España para "la clase estudiantil", pues dadas las circunstancias por las que atravesaba ese país, "el compañero Zavala podría hacer magníficas observaciones desde el punto de vista social".

El ambiente de la Universidad Nacional, cuya autonomía fue legalmente reconocida en 1929, estaba cargado de conciencia social y de interés en la lucha de clases en México y en el mundo. Durante los años que van de 1921 a 1935, la Escuela de Jurisprudencia se asumió como Facultad de Derecho y Ciencias Sociales; en 1929, año en que se fundó el Instituto de Investigaciones Sociales, se abrió, en la Facultad de Derecho, la carrera de Economía; desde 1922, fundada por el estudiante y profesor Daniel Cosío Villegas, se publicó la Revista de la Facultad de Derecho y Ciencias Sociales, cuya primera época — sorteando algunas interrupciones- llegó al volumen VIII en 1929, e inició la segunda en 1930 bajo el título de Revista de Ciencias Sociales de la Facultad de Jurisprudencia. En esas revistas colaboraron profesores y estudiantes, y fueron campo propicio para la crítica constitucional que imponía a la interpretación y las reformas de la Constitución de $1917 .^{3}$

El 14 de abril, cuando Silvio Zavala hacía las gestiones para emprender el viaje a España, se proclamó la República. El joven yucateco tenía en su haber un artículo publicado en 1930, en la Revista de Ciencias Sociales de la Facultad de Jurisprudencia, y otro escrito, que aparecería en la revista Universidad de México, a poco de su llegada a Madrid. Ambos trabajos incidían en derecho constitucional y el proceso revolucionario, principal interés del estudiante que zarpó de Veracruz en mayo de 1931 estimulado y preparado para dar testimonio del momento constitucional de la República Española.

Lira, "Introducción", Zavala, Primeras jornadas, pp. 9-11.

Lira y Ornelas, "Del realismo sociológico a la realidad profesional", pp. 222-230. 


\section{EsCRITOS MEXICANOS}

"Nuestros legisladores y nuestras leyes" es el título del artículo que apareció en 1930 en la Revista de Ciencias Sociales de la Facultad de Jurisprudencia. ${ }^{4}$ Comienza, sin mencionar el nombre del autor, con una cita de Lorenzo de Zavala (ancestro suyo), "un historiador" que ya en 1830 había señalado la contradicción entre "principios que se profesan, instituciones que se adoptan y abusos que se santifican y costumbres que dominan", entre "la soberanía nacional, igualdad de derechos políticos, libertad de imprenta y gobierno popular y la intervención de la fuerza armada, fueros privilegiados, intolerancia religiosa y propietarios de inmensos territorios con derechos semifeudales". Ese choque entre la doctrina "liberalista", asumida en la Constitución republicana federal de 1824 y en la legislación, y posiciones retrógradas, algunas de éstas - como la intolerancia religiosa y los fueros eclesiástico y militar- legalizadas en la Constitución misma, se repetía en épocas sucesivas. En el siglo Xx, la doctrina socialista y el afán de justicia social chocaban con tendencias estacionarias y viejos hábitos, como era evidente en países de Hispanoamérica; México era un claro ejemplo. En Inglaterra ocurría lo contrario, ahí la legislación se nutría de la costumbre judicial, no había ese conflicto entre la marcha institucional y la legislación; pero en los países en que el atraso y la diversidad social eran hechos insoslayables, se acudía al legislador intelectual, informado del progreso doctrinal e institucional, quien, respondiendo con su haber y saber, diseñaba normas ideales, que, una vez promulgadas, resultaban inaplicables y desvirtuadas por la realidad. Ante repetidas evidencias del problema, los intelectuales proponían el estudio previo de la realidad para obrar en consecuencia, diseñando leyes acordes a la realidad; pero lo que ocurría frecuentemente era que los intelectuales, en sus análisis de la sociedad tomaban como realidad aquello que les parecía relevante, por deseable, y diseñaban utopías irrealizables; y no faltaban en el presente, quienes, en nombre costumbres y tradiciones evidentes, sugirieran conformismo o vuelta al pasado, una suerte de contra utopía, por decirlo así, tan utópica en el fondo como aquéllas que se orientaban al futuro.

En México, dada la extensión geográfica del país, su diversidad regional y social, se hallaban componentes sociales y culturales heterogéneos, los yaquis en el noroeste y los mayas salvajes que permanecían aislados en buena parte del territorio de Quintana Roo; si se quería legislar en consecuencia con sus costumbres, ¿había que sancionar institucionalmente esas situaciones?, ¿había que respetar la autoridad de caciques poderosos que arbitrariamente estaban empoderados en muchas partes del país?; ante el hecho generalizado del abandono de la escuela en el medio rural, carácter predominante en el país, ¿había

4 Tomo I, núm. 3, octubre de 1930, pp. 113-119; se recogió en Historia Mexicana, vol. LXI, núm. 1, pp. 278-288. 
que prescindir del principio de la educación elemental obligatoria, liberando a los padres de familia del deber para con sus hijos y olvidar la posibilidad de exigir la responsabilidad consiguiente? Evidentemente, no. En países como el nuestro, el legislador no podía dejar de apuntar fines deseables y de proponer medios para lograrlos, de él se esperaba esa labor orientadora y consecuente, que, pese a las dificultades, había que atender con tino y prudencia. Esa labor, tarde o temprano rendía fruto, o por lo menos, despertaba la atención de la sociedad, que ante disposiciones conformistas con costumbres inconvenientes, reaccionaba con la crítica al legislador. Prueba de ello era lo que ocurría con el artículo 14 de la Constitución de 1857, sancionado positivamente con reformas intrascendentes por el Constituyente de 1917, en acato a la propuesta expresa hecha por Venustiano Carranza, Primer Jefe del Ejército Constitucionalista, en el acto inaugural del Congreso. En obsequio a la costumbre del pueblo mexicano, Carranza decidió dejar de lado las acertadas críticas que desde hacía mucho tiempo se venían haciendo al precepto constitucional que favorecía el abuso del juicio de amparo, entre las cuales destacaba la célebre monografía de Emilio Rabasa, publicada en $1906 .{ }^{5}$

Según el joven autor, en países como México, el legislador debía poner lo que estaba de su parte para acelerar la evolución, valiéndose de los medios de los que disponía. Evidentemente, la visión evolucionista de Emilio Rabasa, cuyas obras nutrieron la crítica constitucional en el siglo $\mathrm{xx},{ }^{6}$ estaba presente en las apreciaciones de Silvio Zavala; las vemos aparecer en el artículo que escribió antes de salir a España junto a las ideas de su profesor de Derecho Constitucional en la Facultad de Jurisprudencia, Hilario Medina, diputado en el Constituyente de 1916-1917 y crítico, opuesto en ese momento, a la inclusión del artículo 14 en la nueva Constitución.

"La teoría constitucional y el momento revolucionario (consideraciones sobre el Congreso Constituyente de 1917)", apareció en la revista Universidad de México, en junio de 1931, poco después de su llegada a Madrid. ${ }^{7}$ En este artículo, Zavala llamó la atención sobre la necesidad de estudiar la Revolución Mexicana — fenómeno del que venían ocupándose profesores y estudiantes de

$5 \quad$ El Artículo 14. Estudio constitucional. México, "El Progreso Latino", 1906 (se ha reeditado a partir de 1955 junto con otra obra de Rabasa, El juicio constitucional. Orígenes, teoría y extensión, publicada en 1920, con prólogo de F. Jorge Gaxiola, por Editorial Porrúa).

6 Un buen ejemplo es la obra de Miguel Lanz Duret, Derecho constitucional mexicano y consideraciones sobre la realidad política en nuestro régimen, publicada en 1931, cuya quinta edición, "revisada y anotada con arreglo a la legislación vigente por el licenciado Roberto Castrovido Gil” apareció en 1959.

7 Tomo II, núm. 8, junio de 1931, pp. 118-128; recogida en Zavala, Primeras jornadas, pp. 25-37. En este libro se encuentran los artículos de Silvio Zavala de los que nos ocuparemos a continuación. Ahí se indica la procedencia de cada uno. En las notas remitimos a las páginas de Primeras jornadas, indicando en el texto nombre y fecha del diario o revista en que aparecieron originalmente. 
la jurisprudencia - desde el punto de vista del derecho constitucional, pues había traído "entre sus convulsiones, una organización nueva". Al hacerse cargo del problema, no pretendía exponer las teorías en cuanto tales - es decir, las que ponderaban quienes se interesaban por la claridad de principios y la gallardía en la exposición-, sino las ideas asumidas por los constituyentes en el momento revolucionario, considerando la obra de quienes escribían después de 1917 para investigar nuestros problemas, pues tal era la pretensión que alentaba la labor de la Facultad de Derecho y Ciencias Sociales.

Comenzó por una cuestión de capital importancia: “¿Cómo debe ser un Congreso Constituyente en México? ¿Debe acoger en su seno, al igual que los europeos, representantes de todas las clases y de todos los partidos, o debe ser de facción?". El planteamiento, así expresado, respondía a impugnaciones críticas que venían haciéndose a la Carta de 1917, desde los días de su discusión y promulgación, por considerarla obra de una facción beligerante que no representaba a la nación mexicana, y cuya versión más conocida era el libro de Jorge Vera Estañol Al margen de la Constitución de 1917, publicado en Los Ángeles, California, en 1920. ${ }^{8}$ Zavala llamó la atención sobre la experiencia mexicana, destacando los inconvenientes del propósito conciliador que guio a los constituyentes mexicanos en el siglo XIX, notablemente al Congreso de 1856-1857; advirtió la ineficiencia de cuerpos que acogieron a conservadores y a liberales moderados y radicales, lo cual no sólo dificultó y retrasó la labor del Constituyente, sino que dio por resultado una carta llena de contradicciones. Según Zavala, el movimiento triunfante en 1855 hubiera podido y debió expresarse mejor de haber conformado un Congreso compuesto sólo de elementos progresistas, pero no fue así. Comparado con el de 1857, el Congreso de 1917 tuvo la ventaja de ser órgano de una sola voz, pues si bien era cierto que hubo en él discusión, ésta se dio entre grupos de un solo partido. "En nuestro desarrollo constitucional, decía Zavala, todo congreso ha sido consecuencia de una lucha", como lo mostraban los ejemplos de 1824,1835 y 1857 , los más notables por su importancia y trascendencia. Si los congresos eran apéndices de luchas de facciones en las que siempre había un vencedor y un vencido, resultaba que, por necesidad el congreso tenía que tener un cariz unitario. Como órganos de un partido, "en México los Congresos Constituyentes deben ser órganos de los partidos triunfadores, deben ser exaltados en sus decisiones y adoptar francamente el criterio de los vencedores". 9

Eso parecía encerrar un grave peligro, pues el triunfo de un partido haría ilusorias las conquistas de constitucionales, fruto de la historia y de la civilización. A esto respondía Zavala con la teoría de su maestro Hilario Medina

8 Vera Estañol, Al margen de la Constitución de 1917, Los Ángeles, California, Wayside Press, California, 1920.

$9 \quad$ Zavala, Primeras jornadas, p. 27. 
- en su momento diputado y miembro de la Segunda Comisión Revisora en el Constituyente de 1917-, quien hablaba de los mínimos constitucionales, reglas decantadas en la experiencia y expresadas en la Constitución, que aseguraban la posibilidad de la convivencia social dentro del orden político, pese a lo radical que éste fuera. Además, decía Zavala, "la exaltación legislativa sufre el lento reflujo regulador del tiempo, que corrige sus extremos, por lo que en México resulta menos peligroso un Congreso Constituyente compuesto de elementos exclusivos del partido triunfante, que otro formado íntegramente de acuerdo con la teoría de la representación". ${ }^{10}$

Luego de abordar el problema de la integración del constituyente - lo que resultaría capital, como veremos, en la consideración del Constituyente español—, trató otros puntos que consideró más relevantes en la Constitución de 1917.

Al hablar del problema del federalismo, asumió la crítica que hizo Emilio Rabasa en La Constitución y la dictadura (1912), cuando, refiriéndose a la Constitución de 1857, advirtió que bajo la apariencia del orden federal había una centralización de la autoridad. Para que el orden federal fuera realidad era indispensable el espíritu público que lo hacía posible y eso sólo se había dado en Jalisco y en Yucatán cuando se optó por la federación en 1824. Sin embargo, advertía Zavala, el Constituyente de 1917 había actuado con tino político al recoger la aspiración federalista que impuso la consideración de la extensión territorial y la diversidad regional del país. Siendo un hecho asumido en diversos momentos del constitucionalismo mexicano, el Congreso de 1917 había obrado en consecuencia.

Otro problema era el sufragio universal. Rabasa advertía que el derecho al voto era una función que implicaba la responsabilidad de los electores, resultado a su vez de cualidades supuestas y de las que carecía la mayoría de la población en México, lo que había llevado a la debilidad de las instituciones. Bajo el orden constitucional de 1857, el Poder Legislativo, entidad impersonal y cambiante debido a la renovación periódica de sus miembros por elección popular, se situaba frente al Poder Ejecutivo, unipersonal, responsable de la política y la administración del país. El Congreso daba o quitaba facultades legales y exigía responsabilidades al Ejecutivo. Para afirmarse frente al Congreso, el Ejecutivo había recurrido a la fuerza, en situaciones extremas, o bien a la cooptación de opositores en las cámaras con el fin de lograr anuencia a sus propuestas o para hacerse de facultades legislativas extraordinarias y legislar sobre materias que consideraba prioritarias. La crítica al sistema y la solución propuesta por Emilio Rabasa en su libro La Constitución y la dictadura estuvieron presentes en el Congreso de 1917; esto es, había que fortalecer al Ejecutivo frente al Legislativo para encauzar las relaciones de ambos poderes. Así lo 
entendió el Constituyente de 1917 cuando procuró y logró el fortalecimiento institucional del presidente con facultades expresas - como el veto- y estableciendo el principio de no reelección para evitar la permanencia personal, que, en los hechos llevaba al empoderamiento de quien se hacía con la presidencia en sucesivos periodos. Pero siendo así, se preguntaba Zavala, “¿ha cesado en virtud de los principios teóricos de la Constitución de 1917 la dictadura institucional de la que habla Rabasa? Por virtud del criterio francamente favorable al Ejecutivo, ¿se ha logrado su permanencia dentro del campo legal y se ha seguido la ponderación de poderes, que era la mira del Constituyente? ¿Ya no encontramos esa irritante desigualdad entre la ley escrita y los acontecimientos?". ${ }^{11}$

En la Constitución de 1917 se encontraba un Ejecutivo predominante y un Legislativo ordenador, situación que había que encauzar para evitar la conformación de un régimen absolutista, que estaba a la vista del observador, pues lo cierto era que el Ejecutivo, usando facultades extraordinarias otorgadas por el Legislativo y auxiliado por comisiones técnicas, venía asumiendo la función legislativa en materias que consideraba prioritarias. Eran esas comisiones las que en realidad llevaban a cabo la función legislativa.

Se conformaba así un régimen que bien podía llamarse absolutista, en el que la función ponderadora de los poderes quedaba a merced del sufragio, problema no resuelto en México, como en otras naciones donde funcionaba mejor el sufragio y en las que, pese a ello, el resultado no era todo lo satisfactorio que podía y debía esperarse, lo cual explicaba las tendencias anti-parlamentarias del momento. El fracaso de los congresos legislativos era un problema para el cual se buscaba solución en la ciencia constitucional. ${ }^{12}$

Tocante al Judicial, con todo lo problemático que según Rabasa implicaba considerarle como poder, el Constituyente de 1917 había adoptado la tesis del crítico de la Constitución de 1857, cuando rechazó la doctrina democrática para la conformación de la Suprema Corte, esto es, la elección popular de los ministros de la Suprema Corte de Justicia, dejando su nombramiento al Congreso de la Unión, quien debía considerar la propuesta de las legislaturas de los estados, y al establecer el principio de inamovilidad judicial. Principio que había echado abajo la última reforma constitucional de 1928, mutilando, advertía Zavala, la obra del Constituyente de Querétaro; pero era posible y deseable que se restableciera, dada la razón que le había asistido cuando consagró ese principio.

Por lo que hace a la nacionalidad, el Constituyente había sabido aprovechar la experiencia, conjugando acertadamente los principios del jus soli y del jus sanguinis, pues abrió la posibilidad de tener como mexicanos por nacimiento a los hijos de padres extranjeros residentes en el país durante seis o más 
años, siempre y cuando, al llegar a la mayoría de edad los nacidos en México declararan su voluntad de ser mexicanos. Esto resultaba conveniente a un país que requería inmigración y población sanas.

También había experiencia y claro sentido histórico en los artículos 39, 40 y 41 , referentes a la titularidad y ejercicio de la soberanía. El Constituyente se atuvo a un criterio propio, no a las críticas que se hicieron al ponderar criterios científicos en las discusiones del Congreso. De esta manera, el Congreso de Querétaro vino a ser el más científico de los congresos que México había tenido hasta entonces, pues había asumido congruentemente la realidad, cumpliendo así con las doctrinas sociológicas exigidas por la moderna legislación.

Con esa afirmación, respuesta expresa a la crítica de Vera Estañol y a la de otros críticos de la Carta de 1917, Zavala daba término al trabajo desarrollado siguiendo, decía, "un método inductivo", ateniéndose a lo que encontró en el análisis de la obra y de la experiencia del Constituyente, manifiestas en la Constitución y en el Diario de debates. Recomendaba aplicar ese método en otros casos, y procuró hacerlo, como veremos, al ocuparse del Constituyente de la República Española.

\section{LA EXPERIENCIA ESPAÑOLA}

"Las próximas Cortes Españolas" es el título del primer artículo escrito en España y publicado en México el 29 de junio en El Nacional. Diario Popular, órgano del Partido Nacional Revolucionario. ${ }^{13}$ Habla del sentido jurídico de los reyes españoles en su larga lucha contra la nobleza, para lograr la integración política de España. Contrastando situaciones, pasa a ocuparse en seguida de la precipitación del momento republicano actual, en el que participaría el pueblo español; habla también del individualismo que lo caracteriza, al grado de decirse que cada español era un partido. La revolución que derribó la monarquía llegaría, ahora y sin más trámite, a las Cortes Constituyentes que en breve habrían de reunirse. Siendo así, esa revolución seguía fraguándose en silencio, había un ambiente cargado de presagios de los que oyó hablar a Fernando de los Ríos, ministro de Gracia y Justicia, en una conferencia que impartió en la Universidad Central de Madrid. De los Ríos era catedrático reconocido, activo militante socialista que reconoció las ventajas de la dictadura en el campo administrativo durante los momentos críticos de la revolución; pese a lo cual, decía Zavala, el orador advirtió que el gobierno republicano la rechazaba, pues quería aprovechar el impulso de la tradición liberal, fincado en la voluntad general, a la cual se someterían los españoles para organizar la república social. Hablaba don

13 Ibid., pp. 39-41. 
Fernando de la libertad y de otros derechos individuales, recordando el juicio de amparo mexicano, surgido en la tradición jurídica española, como medio adecuado para protegerlos, así como de otras instituciones propias a las que se acudiría para fortalecer legalmente la autoridad en el orden constitucional republicano. El proyecto de Constitución se discutiría en una Cámara en la que habría comisiones encargadas de elaborar proyectos que discutiría y votaría el Constituyente. Se trataba de asegurar el respeto a la voluntad general, fundamento y objeto de su labor, acompañándola con criterios racionales y técnicos. Algo frente a lo cual Silvio Zavala manifestó escéptico desacuerdo; según él, lo que urgía en esos momentos era un gobierno firme que se hiciera cargo del orden, pues nada aseguraba la estabilidad del régimen republicano votado en unas elecciones municipales, cuya legalidad se cuestionaba.

El problema político y social era evidente, y de él habló Fernando de los Ríos cuando reconoció la división entre socialistas conciliadores y sindicalistas radicales. Para éstos la organización y los derechos laborales eran todo, mientras que para los socialistas había otros sectores nobles de la vida social que era necesario cultivar. En ese ambiente cargado de confrontaciones y presagios se preparaba la reunión del Constituyente republicano español.

El verano se acercaba y, por lo que vemos en la sucesión de los siguientes artículos, Silvio Zavala aprovechó un viaje a Santiago de Compostela para asomarse al paisaje y a la sociedad de Galicia, sin dejar de atender al momento constitucional de la República Española. ${ }^{14}$ En primer artículo de la suite compostelana — podemos llamarla así, por la variedad y secuencia temática de los textos-, intitulado "El nacimiento de Santiago de Compostela", Zavala nos da una interesante descripción del paisaje gallego, del campo bajo un cielo nuboso en el que la luz parece salir del suelo y no de las alturas; habla de las duras condiciones del medio rural en el que la familia toda, hombres, mujeres y niños, trabajan en las labores del campo; del minifundismo resultante de la lejana y no tan lejana partición de antiguas propiedades de señoríos laicos y eclesiásticos, y del alejamiento de hombres y mujeres de la política, lo cual hace posible la actividad política interesada de quienes se dedican a ella. Notable en ese sentido es el cuarto artículo, "El problema religioso en España" ${ }^{15}$ percibido por Zavala al destacar el significado de la Catedral de Santiago de Compostela en la historia, así como las manifestaciones de la religiosidad en el presente. La importancia de la Iglesia,

14 Se trata de cinco artículos publicados sucesivamente en El Nacional. Los cuatro primeros, con variantes, se recogieron en la revista Universidad de México, no así el quinto ("El factor ciencia en el momento español"), lo que parece extraño, pues es, como veremos, el más interesante para una revista universitaria. Los recogimos y de ellos damos cuenta en Primeras jornadas, pp. 43-62. Zavala, Primeras jornadas, pp. 55-57. 
su predominio palpable en la ciudad misma, donde los edificios históricos señalados con la concha de Santiago daban cuenta de su predominio como propietaria y como organizadora de la vida y del espacio, lo que se había ido circunscribiendo a áreas determinadas para la celebración del culto.

Ese año de 1931 la procesión del Jueves de Corpus (día en que la Iglesia católica celebra la instauración de la eucaristía) se realizó en el interior del templo Catedral, debido al mal tiempo que amenazaba con lluvia. En realidad, Zavala lo deja ver, a la amenaza manifiesta en el desprecio y la ironía con los que la población estudiantil, estimulada por el momento revolucionario, veía la procesión. Los presagios del conflicto debido a la predecible declaración de la separación entre la Iglesia y el Estado en las próximas Cortes Constituyentes, la evidencia de una religiosidad carente de misticismo, en la que los mismos revolucionarios participaban oyendo misas y en otros ritos sacramentales, era señal del agotamiento del sentido religioso de la vida. ${ }^{16}$ Esto último, debemos hacer notar, aparece en la versión publicada en la revista Universidad de México, pero no en El Nacional; donde sí encontramos la aguda descripción de un campesino que oraba ante el magnífico retablo dorado de la Catedral, en una actitud de demanda egoísta, ajena a la imploración y a la fusión mística. Esplendor del culto, no devoción, advierte Silvio Zavala, quien, nos parece, no las traía todas consigo como observador de la experiencia religiosa propiamente dicha, a diferencia de lo que ocurre con la experiencia política, a la que dedicó su atención. ${ }^{17}$

En efecto, los últimos párrafos del artículo publicado en El Nacional ${ }^{18}$ ilustran la agudeza y pertinencia de la percepción del problema político y sociocultural de la religión en el momento constitucional de la República Española, de lo cual preferimos dar cuenta en palabras del autor:

Así, Santiago de Compostela nos habla de una religión pasada que tuvo carácter universal y que extendió su poder en todos los órdenes de la vida. Ahora nos explica una religiosidad objetiva que se prende a los simbolismos para vivir.

¿Qué puede hacer España frente a esto? ¿Va a exterminarlo? ¿Va a reglamentarlo? ¿Lo someterá al poder del Estado?

El intelectual español se da cuenta del valor simbólico de la religiosidad y por ello no pretende destruir la representación objetiva. La obra está en alejar el objeto, en divorciar el sentimiento del símbolo, y para esto se piensa en ridiculizar el simbolismo. ${ }^{19}$

Ibid., véase nota 23 en la p. 57.

Zavala, Primeras jornadas, p. 57.

Ibid., pp. 56-57.

Aquí termina la versión de este artículo publicada en El Nacional del 5 de agosto de 1931. En la versión que apareció en la revista Universidad de México encontramos tres párrafos más sobre la actitud de los estudiantes y de la sociedad en general ante la práctica religiosa. Cfr. Zavala, Primeras jornadas, nota 23, p. 57. 
Terminaba así la versión del artículo publicado en El Nacional, apuntando la secuencia que habría de seguir en ese diario, donde apareció el quinto y último de la serie compostelana, intitulado "El factor ciencia en el momento español", ${ }^{20}$ dedicado a la historia de la Universidad de Santiago de Compostela, cuyo origen encuentra en una obra pía fundada en el siglo Xvi, que habría de transformarse en universidad real. Ese hecho hizo que el compromiso de la intelectualidad universitaria en el momento republicano español resultara inevitable. Así lo veía el estudiante de derecho Silvio Zavala, cuando firmó en Madrid el texto "El factor ciencia en el momento español", momento en que la vieja universidad alojaba a la fuerza joven del movimiento español.

La vida política había influido siempre en la Universidad, pero ésta era más bien un recipiente pasivo y no un ingrediente activo que las determinara. Hoy el caso es inverso. Los estudiantes de Santiago, al igual que todos los de España, han entrado en la vida política del país y pesan en ella de manera preponderante.

Desde hace tiempo se venía pensando que los intelectuales jóvenes serían la base del surgimiento español. Pero su entrada violenta y activa no se esperaba.

El carácter intelectual de la revolución española merece detenidas consideraciones. Los [cuadros] dirigentes están integrados por catedráticos, intelectuales y estudiantes. Los problemas de España son materia de estudio para ellos. Y los tratan científicamente, lo cual significa que los resuelven lentamente. No puede negarse que la campaña contra el Rey ha sido de actividad y que los mismos intelectuales sufrieron prisiones y destierros. Pero ahora que se encuentran en el poder adquieren responsabilidades de gobernantes y, como tienen amplia cultura, no se atreven a dar las acciones violentas que la efervescencia popular exige. En la masa se siente el aguijón del radicalismo y los gobernantes quieren en cambio una evolución pensada, que responda a sus preocupaciones intelectuales. ${ }^{21}$

Para ilustrar la posición de las autoridades republicanas en esa contradictoria situación, Zavala traía a cuento las palabras del ministro de gobernación, quien decía estar tranquilo cuando unos acusaban al gobierno de rapidez, y otros, de lentitud. "Nos hemos quedado en el fiel de la balanza", decía el ministro, cuando, por lo que deja ver Zavala, los platos de la balanza se movían sin cesar.

El experimento español — continuaba Zavala — es por demás interesante. La Universidad se ha trasladado al gobierno y llama a esto un gobierno democrático de calidad; piensa científicamente sobre los problemas y se enorgullece de haber alcanzado un término medio; reconoce prudentemente la fuerza del pueblo y ofrece reformas agrarias para el futuro más o menos lejano. La ley será medio plasmador de anhelos. El elemento científico que gobierna cree en la cultura siempre entendida con traje germánico. 
El único elemento propiamente organizador es el conocimiento que tienen los gobernantes de la necesidad de poder; y pregonan la fuerza como necesaria al orden, vistiendo la idea con ropajes científicos. ${ }^{22}$

La revolución española había sufrido un aplazamiento, por lo pronto había que estar atento a lo que ocurría "Dentro y fuera del Parlamento Español", ${ }^{23}$ título del artículo publicado en El Nacional el 28 de agosto de 1931, en el que daba cuenta de la integración de las Cortes Constituyentes, en la que predominaban los profesionistas y otros representantes de la clase media urbana ("123 abogados; 41 médicos; 50 catedráticos; 13 profesores; 30 periodistas; 16 arquitectos; 6 sacerdotes; 18 industriales y comerciantes; 6 funcionarios públicos; 10 empleados; 11 agricultores; 24 obreros; y pocos farmacéuticos, comisionistas y propietarios, éstos en número de 4"). ${ }^{24}$ Clase media llamada a satisfacer con sensibilidad y eficiencia las demandas de una población heterogénea, alejada de escenarios urbanos y, sobre todo, de las Cortes, cuyos elementos se iban radicalizando.

La situación española parece pues, bifurcada en estos momentos — concluía el joven estudiante-. Una parte de la Revolución se desarrolla dentro del Congreso; por ella no se teme, dada la competencia de los dirigentes. Las Cortes tendrán seguramente momentos de brillo. Pero la parte de la revolución que se desarrolla en las calles no presenta aspectos tan halagadores.

La República de tipo social, democrática, parece equilibrarse pidiendo una base más sólida y, sobre todo duradera. ${ }^{25}$

El artículo estaba firmado en julio de 1931, marcaba el primer compás en la obra que irían componiendo las Cortes y que había que seguir, atendiendo a lo que ofrecía el "Panorama español", título del artículo que siguió y que apareció en El Nacional el 28 de agosto. ${ }^{26}$ Era un panorama complejo, en el que se perfilaban las fuerzas que el gobierno, para serlo, tenía que unir. En el gobierno de Niceto Alcalá Zamora se mezclaban fuerzas que no guardaban afinidad, había moderados de ideas republicanas y ministros socialistas, ésta era la principal fuerza de la República, y no las traía todas consigo.

La disciplina del partido socialista — decía Zavala — ha permitido reprimir los anhelos de su programa, para dedicarse al robustecimiento de la nueva forma de gobierno, pero la unión accidental no puede ser eterna, el socialismo ha

Ibid., p. 61.

Ibid., pp. 63-66.

Ibid., p. 63.

Ibid., p. 66.

Ibid., pp. 67-70. 
recobrado en tiempo más o menos próximo su independencia y posiblemente gobernará España porque su poder es grande. ${ }^{27}$

Pero mientras eso se preveía, el cuadro se complicaba. En Cataluña, el plebiscito del 2 de agosto había dado el triunfo a los autonomistas, la voz que se oía era la de la nación; la Confederación Nacional del Trabajo capitalizaba la voz de los sindicalistas; Galicia manifestaba un claro sentido regionalista; en todas partes el temor de los capitalistas era evidente, había emigración de capitales, dejando una situación difícil, cuyo cuadro general resumía Zavala en estas palabras:

socialismo gubernamental como principal fuerza de la República; grupo moderado de la República que también gobierna, pero que parece destinado a la postergación; grupo catalán autonomista que propugna por las libertades de Cataluña; sindicalismo de tipo anárquico que practica la táctica de acción directa; gallegos autonomistas y religiosos; capitalismo medroso que huye planteando el problema económico. ${ }^{28}$

Pero la visión de la situación de España había que completarla tomando en cuenta la situación general de Europa, donde la crisis económica llevaba a la exaltación del "romanticismo social" y al "paternalismo humanitario", que habían de estrellarse con la realidad. Pues, de no dar a las exigencias presentes la dimensión y el trato adecuados, el rompimiento destructor, estéril a la postre, se haría inevitable. Voces razonantes, como la de José Ortega y Gasset sonaron en las Cortes llamando a los obreros a procurar una España rica, no para hacerse ricos, sino para llegar a ser "menos pobres". A ella se sumaron las de protagonistas del gobierno y del parlamento, voces que, lejos de aminorar la tensión, lograron radicalizar más a los radicales. "Tensión española” es el título del artículo que apareció el 24 de octubre de 1931 en El Nacional. ${ }^{29}$ Zavala destaca el hondo sentido histórico del alma española, su afán de llevar un registro de los problemas. El entusiasmo y euforia de los primeros días de la República habían pasado, había llegado el tiempo de la reflexión. Manuel Azaña, Ministro de Guerra, señalaba que la acción del gobierno debía ser "toda inteligencia, toda prudencia en el manejo de los asuntos públicos", la revolución no era un desfile triunfal, "no merecían el nombre de republicanos quienes asumieran esa actitud”, pues "La República — advertía - trae la libertad; pero la libertad no hace felices a los hombres, los hace simplemente hombres." Ante la actitud y discursos de los miembros del gobierno, acabó de perfilarse el dilema, "Gobierno o Revolución", impuesto por "El problema económico de España”, título y subtítulo del siguiente artículo, que apareció en 
El Nacional el 11 de noviembre de $1931,{ }^{30}$ un mes antes de la publicación de la Constitución de la República.

En las Cortes se había escuchado la voz de Santiago de Alba (1872-1946), elocuente orador con largo historial en la vida política de España, reconocido por su preparación en materia económica y hacendaria. Habló del advenimiento de la "justicia social", en un discurso lleno de información y de señalamientos contra la plutocracia y la banca — en el que estaba presente, claro, la caída del valor de la peseta - y que culminó con una frase que causó sensación: "Por encima del signo monetario está el destino de un pueblo", a la que Zavala dedicó el resto del artículo que venimos siguiendo.

Mostró Zavala el alarde de información y la elocuencia que caracterizaban al orador, también se hizo cargo de la situación general de Europa, en la que, como en otros países, era fácil y estaba de moda hacer señalamientos y promesas, y así había ocurrido; sí, pero a la postre se había visto a un Mussolini retractándose, a Alemania entregándose al auxilio de la banca nacional y extranjera, y a James Ramsey Mac Donald, ${ }^{31}$ en Inglaterra, aceptando la necesidad de abandonar su programa laborista, enajenándose así las simpatías de su partido, pero recibiendo el auxilio del Banco de Inglaterra. Mientras que, en España, Santiago de Alba hablaba, en un vacío institucional, de la necesidad de sortear la crisis financiera, cuya funesta influencia podía reflejarse en la conformación política de España; también, de lograr la estabilidad y el restablecimiento del crédito, mediante el fortalecimiento de la agricultura, del comercio y del empleo, no sólo para braceros, sino para todas las clases y grupos de la sociedad española. Decía luego que, una vez definida la organización legal de la República y saneada la peseta, advendría la "justicia social", culminando con la frase sensacional, "Por encima del signo monetario está el destino de un pueblo".

Hay palabras que no debieran ser analizadas — advierte Zavala-; la frase transcrita, de primera lectura parece llenar todo un vacío, esbozar una acción, demarcar un programa. Es un conjunto [- parece decir conjuro--] que hasta puede arrebatar a determinados temperamentos. Y sin embargo de "por encima", "destino de un pueblo", ¡es tan vago! ¿Qué partido político, a menos de contar con una mayoría aplastante, con una representación moral irreprochable, en fin, con un mandato histórico, se atreve a decir: éste es el destino de mi pueblo? ¿Quién puede llevar a su pueblo por encima de sus signos monetarios, con la olímpica seguridad de que está cumpliendo fines trascendentes, precisos, casi providenciales?

Y llegamos con esto al punto de la situación española, a la cruz de los dos caminos: ¿gobierno o revolución? ¿Economía o destinos del pueblo interpretados

Ibid., pp. 75-78.

1866-1937, laborista, primer ministro en dos ocasiones, 1924 y 1929-1935. Supo negociar ante un Parlamento en el que predominaban los conservadores. 
por quienes sienten que su programa se identifica con esa vida del pueblo? No discutamos si ese programa, si esa línea de partido es o no destino de un pueblo. Vamos a concederlo. Pero esta misma concesión deja en claro la oposición viva entre el signo monetario y las tendencias revolucionarias. ${ }^{32}$

Con esas reflexiones el joven estudiante de derecho llegaría a una comparación entre "La Revolución Mexicana y la Española", título de otro artículo publicado en la revista Universidad de México, ${ }^{33}$ en el que hace ver las dimensiones temporales, geográficas y sociales de ambos movimientos. La desigualdad en el México de Porfirio Díaz, la agitación política y el lirismo democrático de Madero, que quedó atrás para dar lugar a la lucha de facciones.

Calma después de la avalancha: el hombre de estudios viene a interpretar el tremendo sacudimiento y a comentar sus leyes y la nueva organización. En el Congreso de 1917 se reúne en extraño consorcio el abogado joven que sale de la Universidad y revolucionario obscuro que viene de los campos. No siempre se entienden, pero al cabo, construyen la ley fundamental.

Viene el acomodamiento posterior, la estabilización que sigue a la lucha y queda escrita la página revolucionaria mexicana. ${ }^{34}$

El pueblo español no acusaba, seguramente, los contrastes que caracterizaban al mexicano, tenía mayor fijeza, más hondo sentido de su asentamiento, sus elementos estaban más próximos geográfica y socialmente; sí, pero su heterogeneidad conflictiva se hizo visible en el espacio democrático que abrió la opción republicana. Había que preguntarse entonces si

la solución se dará o puede darse en el terreno estrictamente legal y democrático que hasta ahora ha seguido, o desbordará hacia soluciones violentas. Y luego, si el pueblo, o los partidos organizados, van a resolver la naturaleza de la revolución; van a decir si es de izquierda o de derecha; obra burguesa tranquila, o plena de izquierdismo. Dentro de poco ya no se discutirá. Lo que interesa es el color de la Revolución [...], el ciclo puramente político se cierra para entrar a un estudio más profundo.

$[\ldots]$

En México los intelectuales se incorporaron a la corriente central como colaboradores de última hora. Comentaron en leyes la Revolución, en vez de causarla. Una revolución popular usa más sangre que tinta; es poco propicia para la obra del intelectual. En España el intelectual prepara la caída del régimen interior anterior. La causa en gran parte. En admirable posición de

Zavala, Primeras jornadas, p. 77.

Tomo III, núm. 16, febrero, 1932. Primeras jornadas, pp. 79-85.

Zavala, Primeras jornadas, p. 79. 
adoctrinamiento, señaló la ruta, marcó los pasos y triunfó. Escribió con tinta la revolución, no con sangre. ${ }^{35}$

En México la Revolución era un hecho consumado, del cual se partía para analizar la realidad nacional y procurar soluciones políticas que el país reclamaba, considerando la Revolución como hecho legalizado. Así lo veían las generaciones jóvenes; la de Silvio Zavala y otras con las que había convivido en la Universidad del Sureste, en Mérida, y en la Universidad Nacional de México.

En España, la inconformidad con posiciones adoptadas en la agitada discusión de las Cortes estaba a la vista. Se hablaba de "rectificar la República", de la responsabilidad del hombre que se había puesto a "crear historia" (palabras de Ortega y Gasset en las Cortes). El camino revolucionario estaba por delante, se había querido llegar a la definición política sin pasar por la lucha armada, inevitable en el proceso revolucionario, para llegar a la república social democrática. Y siendo así, decía Zavala,

[...] la prueba más dura está por venir y derivará de la nueva clase de materias que hay que enfocar: leyes complementarias, reforma agraria, nuevas bases de organización social [...], ardua labor que lo mismo puede conducir al triunfo definitivo del sentido técnico y democrático, que a un fracaso doloroso, que no será atribuible, seguramente, a defectos propios, sino a la imposibilidad abstracta de la obra. Será la negación de las revoluciones ordenadas de tipo técnico. ${ }^{36}$

Pues tal era la que pretendía llevarse a cabo en España, sin el sacudimiento previo que, una vez acotado por el triunfador, había ofrecido la posibilidad de acomodo — de "plasticidad", dice Zavala - de las fuerzas beligerantes. Las masas, como en todas las revoluciones, reclamaban la primera palabra, no la habían tenido en España y había que dárselas para hacer posible el orden social democrático de la República. Pero, ¿a quiénes?, ¿en qué términos?

En el siguiente y último artículo de política contemporánea que hallamos en su obra, el joven Silvio Zavala se ocupó de "Las izquierdas españolas". Apareció a fines de marzo de 1932, en la revista Crisol, ${ }^{37}$ órgano del Bloque de Obreros Intelectuales (BOI). ${ }^{38}$

Zavala muestra una izquierda dividida en organizaciones irreconciliables. Los socialistas, predominantes numéricamente en las Cortes y en el gobierno, conciliadores en su actitud, pese a su empeño, no habían podido evitar la

Ibid., p. 81.

Ibíd., Primeras jornadas, p. 85 .

Año IV, tomo VII, núm. 39, pp. 162-168. Primeras jornadas, pp. 87-93.

“Crisol. Revista de literatura y crítica. Fundada en enero de 1929 [...] bajo la dirección de Juan de Dios Bojórquez [...]. Su último [número], que fue el 99, apareció en junio de 1938", Diccionario Porrúa de Historia y Geografía de México, tomo I, Quinta ed., 1986, p.765. 
represión violenta de los movimientos sociales; los sindicalistas, anarquistas, dispuestos a la acción violenta e inmediata, y los comunistas, prendados del modelo ruso, al grado que entre ellos no faltaba quién había "visto nevar en Sevilla". Tal parece que Zavala nos dice que a esas fuerzas había que darles la palabra y escucharlas, si era posible, pues de todos modos hablarían - gritarían, mejor dicho - en el conflicto que estaba a la vista y del que ya no se ocupó, pues no siguió tratando temas político-constitucionales contemporáneos.

Con el artículo que venimos comentando, llegamos al final de la etapa estudiantil de Silvio Zavala. En abril de 1932 obtuvo la licenciatura en derecho por la Universidad Central de Madrid, con la tesis "El tercero en el registro mejicano", publicada en Madrid y al año siguiente y en México; ${ }^{39}$ llegamos también al final de su labor de periodista político, es decir, a su manifestación como observador crítico del presente en el que vivía y en el que no dejó de interesarse, como lo muestra su correspondencia privada. ${ }^{40}$ Otros afanes reclamaban su atención y dedicación. En octubre de 1933, defendió la tesis doctoral intitulada Los intereses particulares en la conquista de la Nueva España, de la que hablamos al principio como marca inicial de su obra historiográfica.

\section{EPÍlogo}

La claridad de propósitos y de expresión de Silvio Zavala es notable. En los artículos de los que me he ocupado, hallamos la secuencia de su razonamiento, vemos cómo retoma y desarrolla problemas planteados en textos anteriores. El hecho es evidente a partir del segundo artículo escrito en México "La teoría constitucional y el momento revolucionario. (Consideraciones sobre el Congreso de 1917)", publicado en 1931, en el que desarrolla el problema de la disparidad e incoherencia entre la labor del legislador y la realidad, planteado en el primero, "Nuestros legisladores y nuestras leyes" (1930). Bajo esta idea pone a prueba la Constitución mexicana de 1917 analizando la experiencia del Constituyente, manifiesta en el Diario de los debates. Algo equiparable ocurre con los doce artículos escritos en España, hasta el último, desde "Las próximas Cortes Españolas" hasta "Las izquierdas españolas", donde nos parece que prepara el seguimiento de la lucha que habría de venir, ya anunciada al final de su comparación entre "La Revolución Mexicana y la Española", penúltimo trabajo de Silvio Zavala, de los que aquí nos hemos ocupado y en el que, dicho sea de paso, apreciamos ese lenguaje escueto, preciso, del que hace gala en el título de sus trabajos históricos.

40 Véase Lira, "El tiempo español de Silvio Zavala", pp. 86-90. 
Pienso en el ejemplo que nos ofrece su primer artículo de gran calado (al que precedieron la tesis doctoral y dos libros: Las instituciones jurídicas en la conquista de América y La encomienda indiana, 1935), "Las conquistas de Canarias y América", que apareció en la revista Tierra Firme (I:4, 1935, pp. 81-112 y II:1, 1936, pp. 89-115). En este artículo se advierte la maestría del historiador de las instituciones jurídicas y el gusto, propio de ese género historiográfico, por la historia comparativa, que vemos anunciado en su obra temprana, en "La Revolución Mexicana y la Española", artículo que, junto con "La teoría constitucional y el momento revolucionario (Consideraciones sobre el Congreso de 1917)", éste como primera parte, integran un trabajo redondo, que bien pudiéramos intitular "Los Constituyentes Mexicano de 1917 y Español de 1931 ante el momento revolucionario", marcando así la unidad temática, es decir, claridad de propósito que hemos apreciado en nuestro recorrido por la obra temprana de Silvio Zavala, el estudiante de derecho que definió y defendió su vocación de historiador cuando vivió en España. ${ }^{41}$

\section{Bibliografía}

Lanz Duret, Miguel, Derecho constitucional mexicano y consideraciones sobre la realidad política de nuestro régimen [1931]. Quinta edición, revisada en 1959 con arreglo a la legislación vigente por el licenciado Roberto Castrovido Gil. Prólogo de Alfonso Noriega Jr. México, Norgis Editores, 1959.

Lira, Andrés, "Introducción” a Zavala, Silvio, Primeras jornadas, 1931-1937... (infra), pp. 9-22.

, "El tiempo español de Silvio Zavala: la vocación. Notas sobre un diálogo epistolar", en: Aurelia Valero Pie (coordinadora y editora), Los empeños de una casa. Actores y redes en los inicios de El Colegio de México, México, El Colegio de México, 2015, pp. 77-94.

Lira González, Andrés y Ornelas Hernández, Moisés, "Del realismo sociológico a la realidad profesional. La Escuela Nacional de Jurisprudencia en el periodo 1902-1929”, en: Álvaro Matute Aguirre (coord.), La Universidad durante los gobiernos de Obregón y Calles. De Vasconcelos a la autonomía. México, Universidad Nacional Autónoma de México, 2011, pp. 203-242 ("La UNAM en la Historia de México", t. III).

Rabasa, Emilio, La Constitución y la dictadura. Estudio sobre la organización política de México [1912], Prólogo de Andrés Serra Rojas, México, Editorial Porrúa, 1956.

, El Artículo 14. Estudio constitucional [1906] y El juicio constitucional. Orígenes, teoría y extensión [1920]. Prólogo de F. J. Gaxiola. México, Editorial Porrúa, 1969.

Vera Estañol, Jorge, Al margen de la Constitución de 1917, Los Ángeles, California, Wayside Press, [1920].

${ }^{41} \quad$ Lira, "El tiempo español de Silvio Zavala". 
Zavala, Silvio, "Una jornada anterior": "Nuestros legisladores y nuestras leyes" [1930], Historia Mexicana, vol. LXI, núm. 1, pp. 275-278.

Los intereses particulares en la conquista de la Nueva España [1933], Segunda edición, México, Universidad Nacional Autónoma de México, 1964 (Instituto de Investigaciones Históricas, "Serie Histórica", 10).

, Las instituciones jurídicas en la conquista de América, Madrid, Junta de Ampliación de Estudios e Investigaciones Científicas, Centro de Estudios Históricos (Sección Hispanoamericana), 1935, Tercera edición revisada y aumentada: México, Editorial Porrúa, 1988.

, La encomienda indiana. Madrid, Junta de Ampliación de Estudios e Investigaciones Científicas, Centro de Estudios Históricos (Sección Hispanoamericana), 1935, Tercera edición revisada y aumentada, México, Editorial Porrúa, 1988.

, "Las conquistas de Canarias y de América", Tierra Firme, (I:4, Madrid, 1935, pp. 81-112 y II:1, Madrid, 1936, pp. 89-115).

Biobibliografía de Silvio Zavala. México, El Colegio Nacional, 1999.

- Primeras jornadas, 1931-1937, edición e introducción por Andrés Lira, recopilación y notas por Alberto Enríquez Perea, México, El Colegio de México, 2009. 